\title{
Correction to: Gasification of sewage sludge within a circular economy perspective: a Polish case study
}

\section{Sebastian Werle ${ }^{1}$ (I) $\cdot$ Szymon Sobek $^{1}$}

Published online: 17 August 2019

(C) Springer-Verlag GmbH Germany, part of Springer Nature 2019

\section{Correction to: Environmental Science and Pollution Research} https://doi.org/10.1007/s11356-019-05897-2

The original publication of this paper contains an error.

Correct images for figures 1 and 3 are shown in this paper.

The original article has been corrected.

The online version of the original article can be found at https://doi.org/ 10.1007/s11356-019-05897-2

Sebastian Werle

sebastian.werle@polsl.pl

1 Institute of Thermal Technology, Silesian University of Technology, 44-100 Gliwice, Poland 
Fig. 1 The scheme of the FBG reactor (Werle and Wilk 2011)

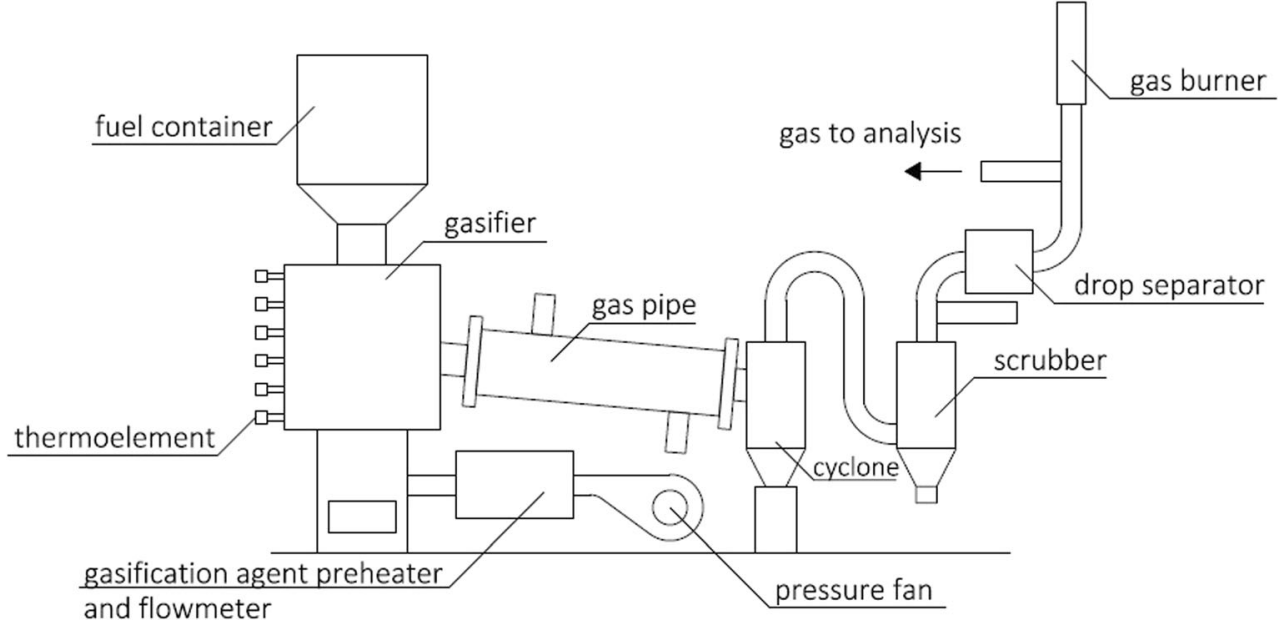

a)

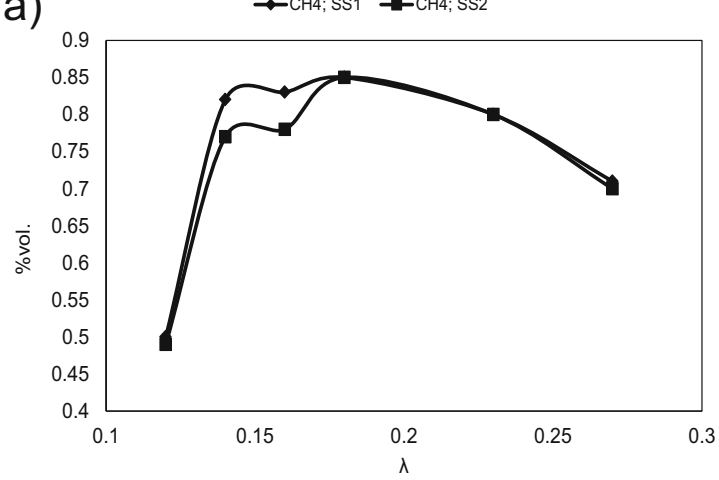

c)

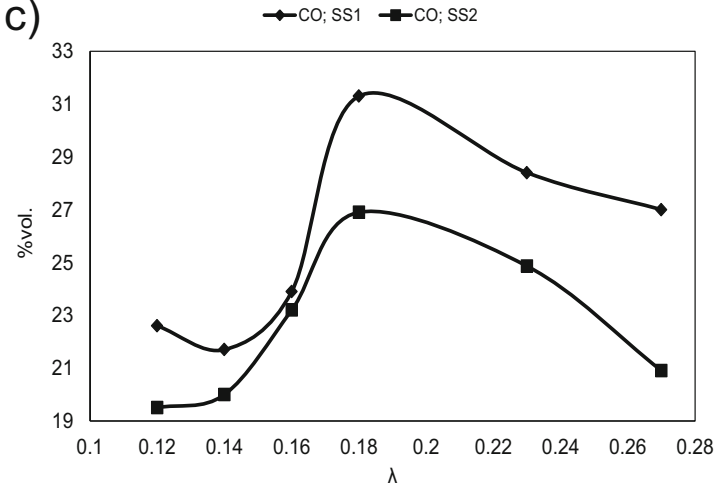

b)

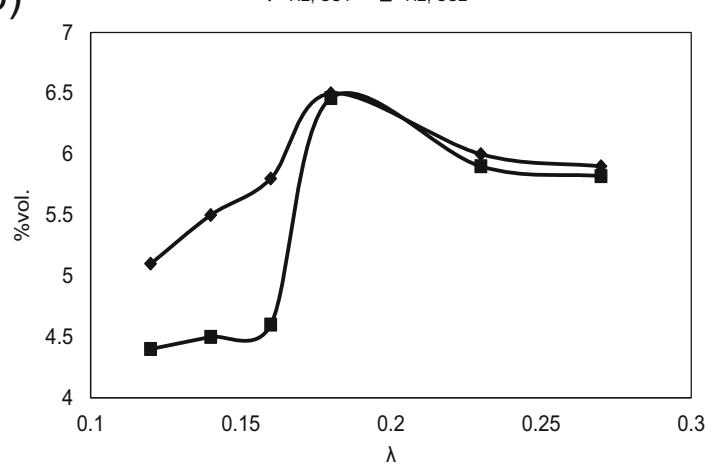

d)

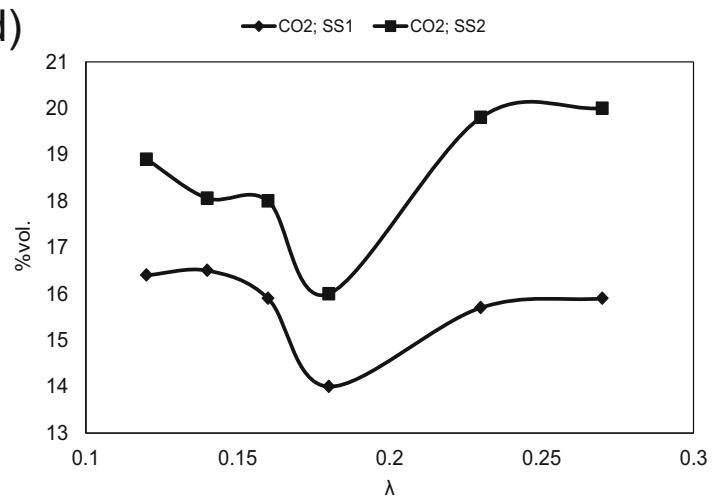

Fig. 3 The volume fraction of main components in gas from SS1 and SS2 gasification process-impact of the air ratio. a $\mathrm{CH}_{4} \cdot \mathbf{b} \mathrm{H}_{2} \cdot \mathbf{c} \mathrm{CO}_{2} \mathbf{d} \mathrm{CO}_{2}$

Publisher's note Springer Nature remains neutral with regard to jurisdictional claims in published maps and institutional affiliations. 